\title{
Mild Behavioral Impairment and Subjective Cognitive Decline predict Mild Cognitive Impairment
}

Zahinoor Ismail*, MD - University of Calgary

Alexander McGirr, MSc, PhD, MD - University of Calgary

Sascha Gill, MSc - University of Calgary

Sophie $\mathrm{Hu}, \mathrm{MSc}-$ University of Calgary

Nils D. Forkert, PhD - University of Calgary

Eric E. Smith, MPH, MD - University of Calgary

*Corresponding Author:

Zahinoor Ismail

3280 Hospital Dr. NW Calgary AB

Canada T2N $4 \mathrm{Z} 6$

403-210-6900

ismailz@,ucalgary.ca

Manuscript word count: 3555 words (max 4500)

Abstract limit 250 words

Max 50 refs

Introduction 250 words 


\begin{abstract}
Objective: Better methods for detecting preclinical neuropathological change are required for prevention of dementia. Mild behavioral impairment (MBI) and subjective cognitive decline (SCD) can represent neurobehavioral and neurocognitive axes of early stage neurodegenerative processes, which are represented in Stage 2 of the NIA-AA Alzheimer's disease research framework. Both MBI and SCD may offer an opportunity for premorbid detection. We test the hypothesis that MBI and SCD confer additive risk for incident cognitive decline.
\end{abstract}

Methods: Participants were cognitively normal older adults followed up approximately annually at Alzheimer's Disease Centers. Logistic regression was used to determine the relationship between baseline classification (MBI+, SCD+, neither (MBI-SCD-), or both $(\mathrm{MBI}+\mathrm{SCD}+))$ and cognitive decline, defined by Clinical Dementia Rating (CDR) total score, at 3 years.

Results: Of 2769 participants (mean age=76; 63\% females), 1536 were MBI-SCD-, 254 MBI-SCD+, 743 MBI+SCD-, and $236 \mathrm{MBI}+\mathrm{SCD}+$. At 3-years, 349 individuals (12.6\%) developed cognitive decline to $\mathrm{CDR}>0$. Compared to SCD-MBI-, we observed an ordinal progression in risk, with ORs [95\% CI] as follows: 3.61 [2.42-5.38] for MBI-SCD+ (16.5\% progression), 4.76 [3.57-6.34] for MBI+SCD-, (20.7\% progression) and 8.15 [5.71-11.64] for $\mathrm{MBI}+\mathrm{SCD}+(30.9 \%$ progression $)$. 
Conclusion: MBI in older adults alone or in combination with SCD is associated with a higher risk of incident cognitive decline at 3 years. The highest rate of progression to MCI is observed in those with both MBI and SCD. Used in conjunction, MBI and SCD could be simple and scalable methods to identify patients at high risk for cognitive decline for prevention studies. 


\section{Introduction}

Commonly cited reasons for high costs and poor outcomes in Alzheimer's disease (AD) clinical trials are screen failures and poor recruitment of early phase illness ${ }^{1,2}$.

Identification of sensitive and specific premorbid indicators of emergent pathology is a priority $^{1}$. A leading strategy to detect preclinical disease is to focus on subjective cognitive decline (SCD), a perceived decline in cognitive ability in the absence of objective findings $\mathrm{s}^{3,4}$, which has been associated with amyloid burden ${ }^{5}$ and incident cognitive decline and dementia ${ }^{6}$.

An emerging strategy is to capture early behavioral manifestations of dementia ${ }^{7}$ that occur in $30 \%$ of $\mathrm{AD}$ patients prior to cognitive manifestations ${ }^{8}$. Mild behavioral impairment (MBI) is a validated syndrome that serves as a sensitive transitional state marker for dementia syndromes. MBI is characterized by the emergence in later life of persistent neuropsychiatric symptoms, and may be an index manifestation of dementia, evident before cognitive symptoms ${ }^{9}$. MBI is associated with cognitive decline ${ }^{10}$, faster progression to dementia ${ }^{11,12}$, known $\mathrm{AD}$ genetic $\operatorname{loc} i^{13,14}$, greater axonal $\operatorname{loss}^{15}$, and amyloid burden in patients with normal cognition ${ }^{16}$.

Both MBI and SCD are reflected in the NIA-AA AD research framework in Stage 2

(Table 1, Figure 1) ${ }^{17}$. To our knowledge, there have been no large prospective studies examining the prognostic utility of MBI and SCD in a sample of objectively normal individuals at higher risk for dementia. We hypothesized that cognitive and behavioral 
medRxiv preprint doi: https://doi.org/10.1101/2020.05.24.20112284; this version posted May 25, 2020. The copyright holder for this preprint

changes in late life may represent coherent or divergent manifestations of emerging pathology that can be leveraged to identify sensitive windows for intervention.

\section{Methods}

Source population: National Alzheimer's Coordinating Center (NACC)

Data used in this study were obtained from the NACC database

(https://www.alz.washington.edu/). NACC was established by the National Institute on Aging (NIA) and consists of multiple NIA-funded Alzheimer's Disease Research Centers (ADRCs) recruiting and collecting data on subjects with cognitive function ranging from normal to dementia. The NACC Uniform Data Set (UDS) is a large longitudinal dataset that includes demographic and standardized clinical data collected approximately annually. All test centers administered standardized forms and informed consent was collected from all subjects and their informants. Detailed information on the cohort and neuropsychological battery of tests included in UDS is described elsewhere ${ }^{18-20}$. NACCUDS with a December 2018 data freeze date was used for this study.

\section{Patient Groupings}

MBI status was derived from UDS using a published algorithm ${ }^{21,22}$ for transformation of the Neuropsychiatric Inventory Questionnaire (NPI-Q) ${ }^{23}$ items to MBI domains. Specifically, ten NPS domains from the NPI-Q were used to populate the five MBI domains of decreased motivation (NPI-Q apathy/indifference); emotional/ affective dysregulation (NPI-Q depression/dysphoria, anxiety, elation/euphoria); impulse dyscontrol (NPI-Q agitation/aggression, irritability/lability, aberrant motor behavior); 
medRxiv preprint doi: https://doi.org/10.1101/2020.05.24.20112284; this version posted May 25, 2020. The copyright holder for this preprint

social inappropriateness (NPI-Q disinhibition); and abnormal perception or through content (NPI-Q delusions, hallucinations). To obtain the MBI total score, these five transformed domain scores were added together. As the NPI-Q has a reference range of one month, to meet MBI persistence of symptoms criteria, individuals with MBI total score $>0$ at two consecutive annual visits were classified as MBI positive $(\mathrm{MBI}+)$ and their MBI scores were calculated as the average over the interval. Those with no NPS were classified as MBI negative (MBI-) for comparison. To determine subjective cognitive decline, the SCD-Initiative Workgroup criteria ${ }^{22}$ were used as a framework and operationalized in NACC as follows: 1) endorsement by participant of a decline in memory on the UDS B9 form; and 2) normal cognition.

Figure 2 shows the step-by-step process for participant inclusion/exclusion. All NACC participants from 2005-2018 were initially considered for inclusion. The initial step was to classify based on MBI status (MBI+/-) and those with transient NPS not meeting MBI duration criteria were excluded. Study endpoint was chosen a priori to be 3 years to reflect clinical practice and design of observational cohort studies. This approach provided a concrete time frame to assess change, in order to balance the need to wait long enough to see change, but to also minimize attrition that would accrue due to age-related mortality and other diseases that confound cognitive assessments. We included participants with a follow-up visit $\sim 3$ years after the baseline visit to evaluate the change in Clinical Dementia Rating Scale (CDR ${ }^{\circ}$ Dementia Staging Instrument) ${ }^{24}$ score over time and participants were excluded if they were missing the 3 -year study visit. SCD 
medRxiv preprint doi: https://doi.org/10.1101/2020.05.24.20112284; this version posted May 25, 2020. The copyright holder for this preprint

status was then determined and participants with a baseline CDR $>0$ were excluded.

Finally, those with a baseline diagnosis of a psychiatric illness were excluded.

\section{Study Variables}

Baseline variables included age, sex, education, and MBI/SCD category. Our primary outcome measure, the CDR, consists of six domains: memory, orientation, judgment and problem solving, community affairs, home and hobbies, and personal care ${ }^{24}$. In our study, we used the global standard CDR score, which assesses the level of impairment, and ranges in severity from no impairment $(\mathrm{CDR}=0)$, questionable impairment $(\mathrm{CDR}=0.5-$ corresponding to $\mathrm{MCI})$, mild impairment $(\mathrm{CDR}=1$ - corresponding to mild dementia), to moderate to severe impairment $(\mathrm{CDR}=2-3)$. All participants had a baseline CDR score of 0 , and we measured the change in cognitive status at 3 years.

\section{Statistical Analysis}

Categorical variables were analyzed with $\chi^{2}$ test, and the continuous variables were analyzed using one way ANOVA. We defined patient groups ordinally according to the absence or presence of SCD, MBI, or both at baseline. Cognitive decline was defined as CDR $>0$ after 3 years. We tested the ordinal by ordinal association of patient groups and cognitive decline using linear by linear association and gamma statistic, and computed odds ratios (OR) for cognitive decline using logistic regression with the patient group having neither SCD nor MBI at baseline serving as the reference group. In this model, we included terms for all variables reaching statistical significance $(p<0.05)$ in the univariate 
analyses to calculate Adjusted Odds Ratios (AOR). All analyses were conducted in SPSS v24 (IBM Corporation) with $\alpha$ set at 0.05 .

\section{Results}

The final sample consisted of 2769 participants with $\mathrm{CDR}=0$ at baseline. Participants had neither MBI nor SCD (MBI-SCD-; n=1536); SCD but no MBI (MBI-SCD+; n=254); MBI but no SCD (MBI+SCD-; n=743); and both MBI and SCD (MBI+SCD+; n=236). There were significant differences in sex, age, ethnicity, and a history of hypertension but no significant differences regarding any other clinical and demographic characteristic investigated (Table 2).

Over the 3 years of follow-up, $349 / 2769$ (12.6\%) individuals had evidence of cognitive decline. In Figure 3A, we present the incidence of cognitive decline according to the baseline presence of MBI, SCD, or their combination. Of the $1536 \mathrm{MBI}-\mathrm{SCD}-$ participants, $80(5.21 \%)$ progressed to $\mathrm{CDR}>0$ at 3 years, while progression for MBI$\mathrm{SCD}+$ was 42/254 (16.54\%), MBI+SCD- was 154/743 (20.73\%), and MBI+SCD+ was 73/236 (30.93\%). This highly significant difference (linear-by-linear=193.24, $\mathrm{df}=1$, $p<0.001$ ) also revealed a strong ordinal by ordinal symmetry (gamma $=0.56, \mathrm{SE}=0.031$, Approximate $\mathrm{T}=12.62, p<0.001)$.

To quantify the increased risk of incident cognitive decline according to these baseline risk definitions, we used logistic regression to generate adjusted odds ratios (AOR) and 95\% confidence intervals $(\mathrm{CI})$. The odds of change to $\mathrm{CDR}>0$ was 8.15 times higher for 
MBI+SCD+ than MBI-SCD- (95\%CI 2.42-5.38, $p<0.001 ; \mathrm{AOR}=7.87,95 \% \mathrm{CI}: 5.46-$

11.35, $p<0.001)$. Those with MBI+SCD- had 4.76 times the odds of increased CDR than MBI-SCD- individuals (95\%CI 3.57-6.34, $p<0.001$; AOR=4.26, 95\%CI: 3.17-5.73, $p<0.001)$. Those with MBI-SCD+ had 3.76 times the odds of increased CDR than MBISCD- individuals (95\%CI 5.71-11.64, $p<0.001$; AOR=3.30, 95\%CI: 2.20-4.96, $p<0.001)$. Covariates for all models were age, sex, ethnicity, and history of hypertension.

We then examined the distribution of CDR scores at follow-up according to the presence of SCD, MBI, or both at baseline (Figure 3B), which revealed that the magnitude of progression from CDR 0 increased incrementally according to baseline characteristics. This distribution in CDR scores was significantly different across groups (linear-bylinear $=165.96, \mathrm{df}=1, p<0.001$ ), with strong ordinal by ordinal symmetry (gamma $=0.69$, Approximate $\mathrm{T}=4.40, p<0.001)$.

Over the 3 years of follow-up, 2/1536 of the MBI-SCD- participants $(0.1 \%)$ progressed to CDR $\geq 1$ (dementia), compared to $1 / 254$ of the MBI-SCD+ participants $(0.4 \%), 20 / 743$ of the MBI+SCD- participants $(2.7 \%)$, and $3 / 236$ of the $\mathrm{MBI}+\mathrm{SCD}+$ participants $(1.3 \%)$

(Figure 3C). To quantify this increased risk of incident dementia over the follow-up period, we used logistic regression. Compared to MBI-SCD-, the odds of progressing to dementia over the follow-up period were 21.21 (95\%CI: 4.94-91.01, $p<0.001$; $\mathrm{AOR}=19.23,95 \% \mathrm{CI}: 4.40-84.03, p<0.001)$ for $\mathrm{MBI}+\mathrm{SCD}$ - and 9.87 (95\%CI: $1.64-59.41$, $p<0.05 ; \mathrm{AOR}=9.33,95 \% \mathrm{CI}: 1.53-56.78, p<0.05)$ for $\mathrm{MBI}+\mathrm{SCD}+$ individuals. Covariates for all models were age, sex, ethnicity, and history of hypertension. 
medRxiv preprint doi: https://doi.org/10.1101/2020.05.24.20112284; this version posted May 25, 2020. The copyright holder for this preprint

\section{Discussion}

In an analysis of a longitudinal cohort of 2769 participants, we demonstrated that those who are cognitively unimpaired, have MBI, SCD, or both MBI and SCD lie on a continuum of risk for incident cognitive decline and dementia. Importantly, MBI was associated with progression to $\mathrm{CDR}>0$ at the three year visit even when cognitive symptoms were absent (i.e. in the absence of $\mathrm{SCD}$ ). The OR for progression to $\mathrm{CDR}>0$ was numerically higher in persons with MBI alone (20.7\% progression rate; OR 4.76) compared with SCD alone (16.5\% progression rate; OR 3.76) but this different was not statistically significant. MBI was also associated with progression from normal cognition to dementia $(C D R \geq 1)$, with very high ORs (OR of 19.23 for MBI alone and 9.87 for $\mathrm{MBI}+\mathrm{SCD}+$ ) but these analyses were based on only a handful of events.

In the new NIA-AA research framework for $\mathrm{AD}$, stage 2 is a distinct transitional stage between stage 1 (asymptomatic) and stage 3 (mildly impaired). This framework is termed clinical staging rather than cognitive staging to recognize that early clinical manifestations of AD may be either cognitive or neurobehavioral ${ }^{17}$. As per the framework "an individual may be placed into stage 2 on the basis of neurobehavioral symptoms alone, that is, without evident cognitive decline". Importantly, "mild neurobehavioral changes - for example, changes in mood, anxiety, or motivation — may coexist. In some individuals, the primary complaint may be neurobehavioral rather than cognitive. Neurobehavioral symptoms should have a clearly defined recent onset, which persists and cannot be explained by life events" ${ }^{\prime 17}$. The acknowledgement of early neurobehavioral symptoms in the NIA-AA framework is consistent with the 
medRxiv preprint doi: https://doi.org/10.1101/2020.05.24.20112284; this version posted May 25, 2020. The copyright holder for this preprint

conceptualization of MBI by the 2016 International Society to Advance Alzheimer's Research and Treatment - Alzheimer's Association (ISTAART-AA) MBI criteria9. The MBI criteria mandate that NPS emerge in later life and represent a change from longstanding patterns of behaviour (i.e. NIA-AA stage 2 "clearly defined recent onset"), persist for $\geq 6$ months (i.e. NIA-AA stage 2 "which persists"), and cannot be better accounted for by medical or psychiatric conditions, including life stressors (i.e. NIA AA stage 2 "cannot be explained by life events").

We excluded participants with a psychiatric diagnosis at baseline as MBI diagnosis is precluded by the presence of a psychiatric disorder. In advance of cognitive changes, there is conflicting evidence regarding the links between psychiatric history and dementia risk $^{25,26}$. The confounds in the study of the relationship between psychiatric symptoms and incident dementia have in part been due to a psychiatric nosology that is silent on the natural history of symptoms. However, several large longitudinal cohorts have provided compelling evidence that the age of onset of psychiatric symptoms is a crucial factor in determining the nature of these symptoms. These studies suggest that the later in life the onset of psychiatric symptomatology, the more likely these symptoms represent the early stages of a neurodegenerative process, that precede dementia by $5-11$ years ${ }^{27-30}$. In a 5year study of older adults, MBI had a higher conversion rate to dementia than a psychiatric comparator group consisting of late life psychiatric disorders ${ }^{11}$. From a community cohort of 9,931 participants, the emergence of MBI was associated with decline in attention and working memory at 1 year ${ }^{10}$. In psychiatry and neurology specialty clinic samples, incidence of dementia was higher for MBI than other psychiatric 
medRxiv preprint doi: https://doi.org/10.1101/2020.05.24.20112284; this version posted May 25, 2020. The copyright holder for this preprint

disorders $^{11,12}$. This evidence suggests that chronic and recurrent psychiatric symptoms reflect a psychiatric disorder framed in the context of psychiatric conditions, sometimes neurodevelopmental in origin, supporting exclusion from our analysis. In contrast late onset psychiatric symptoms may be prodromal or precursor to cognitive decline and dementia, framed in the context of neurodegeneration. The ISTAART-AA MBI criteria were developed with an appreciation of the difference between pre-dementia behavioral changes and psychiatric disease in later life $^{9}$, and are now harmonized with the biological understanding of $\mathrm{AD}$ in the NIA-AA clinical staging framework.

Neurobiological evidence supports the association between MBI and neurodegenerative disease. For example, cortical amyloid has been shown to moderate the association between worsening depressive symptoms and declining cognition ${ }^{31}$, while subcortical amyloidosis has been associated with anxiety in cognitive normals ${ }^{32}$. Studies have linked MBI with known AD genetic loci ${ }^{13}$, and have demonstrated that the relationship between $\mathrm{AD}$ genetic risk and cognition in healthy older adults is stronger in individuals with $\mathrm{MBI}^{14}$. Using machine learning models, MBI was determined to be as powerful as hippocampal volume in predicting dementia diagnosis 40 months later in a group of nondemented older adults ${ }^{33}$. In a study of 96 older adults with normal cognition, greater MBI burden was associated with higher PET amyloid signal, which was not dependent on the presence or absence of $\mathrm{SCD}^{16}$. Longitudinal data has also linked the validated biomarker neurofilament light (NfL) with MBI. In a study of 584 non-demented patients, MBI was associated with faster plasma NfL accumulation over 2 years compared to patients without MBI, with time*MBI status the only significant interaction to predict change in 
medRxiv preprint doi: https://doi.org/10.1101/2020.05.24.20112284; this version posted May 25, 2020. The copyright holder for this preprint

NfL concentration ${ }^{15}$. These biological links between MBI and known dementia mechanisms, further link MBI and NIA-AA clinical stage 2 disease. Thus, an increasing body of evidence suggests that MBI is likely a consequence of emerging dementia proteinopathies, manifesting independently of cognitive symptoms.

SCD is also represented in Stage 2 AD of the NIA-AA research framework in which there is subjective or objective evidence of subtle decline, not meeting criteria for objective impairment. On the AD continuum, subjective complaints of cognitive impairment would be considered evidence of subtle cognitive decline as transitional to a more impaired stage, and attributable to the pathologic process ${ }^{17}$. Meta-analysis of large longitudinal cohorts has shown that SCD is associated with ORs of 6 of progression to MCI and 2 for progression to dementia over a mean of 4.8 years $^{6}$. In one study, up to $74 \%$ of people aged 70 years and older who performed normally on standard cognitive tests self-reported a subjective decline in cognitive functioning. Of these $74 \%, 14 \%$ represented a group at higher risk of incident $\mathrm{MCI}^{34}$. In a study of older adults with $\mathrm{SCD}$, ascertained using a composite score of 3 rating scales, $26 \%$ were determined to be $\mathrm{A} \beta+^{5}$. However, significant inter-site variability in the association between SCD and abnormal cerebrospinal fluid amyloid levels has been attributed to different recruitment approaches and a lack of standardized case definitions and ascertainment ${ }^{35}$. There can be other contributors to subjective complaints of cognitive decline. Medical issues, stressors and even medications (such as those with an anticholinergic burden) can result in subtle cognitive impairment in the absence of neurodegeneration, which might compromise the specificity of the SCD construct. Nonetheless, as with MBI, SCD reflects emerging 
medRxiv preprint doi: https://doi.org/10.1101/2020.05.24.20112284; this version posted May 25, 2020. The copyright holder for this preprint

dementia proteinopathies associated with $\mathrm{AD}$ and is the index clinical manifestation of the neurodegenerative process for some.

The source of information for MBI status in our study was the NPI-Q ${ }^{23}$ completed by an informant. The NPI-Q was developed to measure NPS in dementia, and the symptoms as described are relevant to an aging population with neurodegenerative disease. Informant reports have shown to be more reliable assessments of NPS in neurodegenerative disease to minimize the impact of anosognosia ${ }^{36}$. Coincidentally, in another study of SCD, confirmation of decline by an informant was the best predictor of worse cognitive performance and lower gray matter volumes ${ }^{37}$. Anosognosia is also important to consider in the assessment of SCD. The INSIGHT-PreAD study showed that patients with low cognitive awareness (subjects reporting fewer difficulties than their relatives do) showed greater amyloid burden and lower cortical metabolism, compared to the high awareness group $^{38}$. Thus, self-report of symptoms alone, whether cognitive or behavioral, may not be adequate to capture early disease.

MBI and SCD intersect in some instances and may measure similar features in different ways. For example, a study of SCD determined that worries about self-perceived functioning were associated with $\mathrm{A} \beta$ positivity, rather than subjective cognitive functioning itself ${ }^{39}$. Worries or concerns are included in the SCD plus criteria, proposed to increase specificity for detecting preclinical $\mathrm{AD}^{3}$. Worry is also a component of the $\mathrm{MBI}$ affective dysregulation domain, which includes emergent mood and anxiety symptoms. A large Korean cohort study found a similar result with SCD and depressive symptoms (also 
medRxiv preprint doi: https://doi.org/10.1101/2020.05.24.20112284; this version posted May 25, 2020. The copyright holder for this preprint

a component of MBI affective dysregulation): SCD and depressive symptoms were both independent predictors of dementia, but together contributed to dementia development through their interaction ${ }^{40}$. The approach to psychiatric symptomatology in SCD has generally utilized traditional constructs of personality (e.g. neuroticism) and psychiatric conditions $^{41-43}$. However, a change in personality to greater neuroticism ( which is a neurodevelopmental construct) can also be framed as the emergence of MBI affective dysregulation, if considered in a neurodegenerative frame of reference ${ }^{41}$. This intersection of MBI and SCD is consistent with both constructs being represented in NIA-AA stage 2 AD.

Our data indicate that in cognitively normal older adults, the neurobehavioural axis of dementia risk represented by $\mathrm{MBI}$, and neurocognitive axis of dementia risk represented by SCD, have complementary associations with the risk of progression to $\mathrm{MCI}$ and dementia. As operationalized in our study, MBI appears to be at least as strong a risk factor for progression to MCI or dementia as SCD and the two constructs have overlapping features. The combination of both MBI and SCD was associated with the highest risk.

There are practical implications of our findings. Clinically, as a complement to screening for subjective and objective cognitive symptoms in older adults, incorporating MBI into clinical assessments may provide complementary information and better risk stratification $^{44}$. Not infrequently, dementia patients are first given a psychiatric diagnosis when presenting with a neuropsychiatric symptom, resulting in delays to treatment ${ }^{45,46}$. 
Identifying MBI would prompt clinicians to consider neurocognitive disorders on the differential diagnosis, and flag patients who might benefit from imaging or further workup.

These findings also have clinical trial implications. Research and development costs are higher for Alzheimer's disease (AD) than other therapy areas due to lower success rates and longer development times ${ }^{2}$. Despite the fact that changes in brain structure and function occur up to 20 years before gross memory impairment ${ }^{47}$, screening for preclinical disease is expensive and inefficient, usually requiring detailed neuropsychological testing, and amyloid/tau PET imaging or CSF analysis (or both). Leveraging the ease of measurement of MBI, in conjunction with SCD, could be an inexpensive and scalable method to select patients at highest risk for biomarker positivity and cognitive decline. For dementia prevention trials, combining MBI and SCD can increase yield and improve signal-to-noise ratios for clinical trial screening. This reduction in screen failures can increase trial efficiency and decrease trial cost.

\section{Limitations:}

The NACC participants are mostly white, highly educated, volunteers seeking care and consultation at urban, university-based centers, and the finding may not generalize to other settings. For MBI case ascertainment, we used the NPI-Q ${ }^{23}$ rather than the validated MBI checklist (MBI-C) ${ }^{48-50}$ which was developed specifically to diagnose MBI. However, we used a validated algorithm to convert NPI-Q scores to MBI-C scores and 
required NPS at 2 consecutive visits to match the MBI criterion of new, persistent symptoms.

\section{Conclusions:}

We have demonstrated that MBI, a neurobehavioural syndrome, is an important predictor of incident cognitive decline at 3 years in cognitively normal subjects supporting the use of MBI as a powerful risk assessment tool. Our findings suggest that MBI is at least as useful as SCD in assessing risk for incident cognitive decline and dementia, and that the two constructs are likely complementary. Assessment of the neurobehavioral and neurocognitive axes at the same time are required in cognitively normal individuals to better define their risk. Our findings add support to the inclusion of later life emergent and persistent neurobehavioural symptoms in the NIA-AA research framework for AD. 
medRxiv preprint doi: https://doi.org/10.1101/2020.05.24.20112284; this version posted May 25, 2020. The copyright holder for this preprint (which was not certified by peer review) is the author/funder, who has granted medRxiv a license to display the preprint in perpetuity.

\section{Acknowledgements:}

Grant support included the Alzheimer Society of Calgary via the Hotchkiss Brain

Institute (Ismail) and the Canada Research Chairs program (Forkert). We also

acknowledge the Mathison Centre for Mental Health Research \& Education, and the Ron and Rene Ward Centre for Healthy Brain Aging for support.

Data used in this study was from the NACC database which is funded by NIA/NIH Grant U01 AG016976. NACC data are contributed by the NIA-funded ADCs: P30 AG019610 (PI Eric Reiman, MD), P30 AG013846 (PI Neil Kowall, MD), P30 AG062428-01 (PI James Leverenz, MD) P50 AG008702 (PI Scott Small, MD), P50 AG025688 (PI Allan Levey, MD, PhD), P50 AG047266 (PI Todd Golde, MD, PhD), P30 AG010133 (PI Andrew Saykin, PsyD), P50 AG005146 (PI Marilyn Albert, PhD), P30 AG062421-01 (PI Bradley Hyman, MD, PhD), P30 AG062422-01 (PI Ronald Petersen, MD, PhD), P50 AG005138 (PI Mary Sano, PhD), P30 AG008051 (PI Thomas Wisniewski, MD), P30 AG013854 (PI Robert Vassar, PhD), P30 AG008017 (PI Jeffrey Kaye, MD), P30 AG010161 (PI David Bennett, MD), P50 AG047366 (PI Victor Henderson, MD, MS), P30 AG010129 (PI Charles DeCarli, MD), P50 AG016573 (PI Frank LaFerla, PhD), P30 AG062429-01(PI James Brewer, MD, PhD), P50 AG023501 (PI Bruce Miller, MD), P30 AG035982 (PI Russell Swerdlow, MD), P30 AG028383 (PI Linda Van Eldik, PhD), P30 AG053760 (PI Henry Paulson, MD, PhD), P30 AG010124 (PI John Trojanowski, MD, PhD), P50 AG005133 (PI Oscar Lopez, MD), P50 AG005142 (PI Helena Chui, MD), P30 AG012300 (PI Roger Rosenberg, MD), P30 AG049638 (PI Suzanne Craft, PhD), P50 AG005136 (PI Thomas Grabowski, MD), P30 AG062715-01 (PI Sanjay Asthana, 
MD, FRCP), P50 AG005681 (PI John Morris, MD), P50 AG047270 (PI Stephen

Strittmatter, MD, PhD).

Funding: Grant support included the Alzheimer Society of Calgary via the Hotchkiss Brain Institute (Ismail). We also acknowledge the Mathison Centre for Mental Health Research \& Education, and the Ron and Rene Ward Centre for Healthy Brain Aging for support.

Declaration of Interest: Dr. Ismail reports grants and personal fees from Janssen, and personal fees from Lundbeck and Otsuka, outside the submitted work; Dr. Smith reports personal fees from Alnylman Pharmaceuticals, personal fees from Portola Pharmaceuticals, personal fees from Biogen, outside the submitted work; no other authors have financial interests with commercial interests. 
medRxiv preprint doi: https://doi.org/10.1101/2020.05.24.20112284; this version posted May 25, 2020. The copyright holder for this preprint (which was not certified by peer review) is the author/funder, who has granted medRxiv a license to display the preprint in perpetuity. It is made available under a CC-BY-NC-ND 4.0 International license .

\section{References:}

1. Mortby ME, Black SE, Gauthier S, et al. Dementia clinical trial implications of Mild Behavioral Impairment. Int Psychogeriatr. 2018;30(2):171-175.

2. Gauthier S, Albert M, Fox N, et al. Why has therapy development for dementia failed in the last two decades? Alzheimers Dement. 2016;12(1):60-64.

3. Jessen F, Amariglio RE, Van Boxtel M, et al. A conceptual framework for research on subjective cognitive decline in preclinical Alzheimer's disease. Alzheimers Dement. 2014;10(6):844-852.

4. Slot RE, Verfaillie SC, Overbeek JM, et al. Subjective Cognitive Impairment Cohort (SCIENCe): study design and first results. Alzheimer's research \& therapy. 2018;10(1):76.

5. Amariglio RE, Becker JA, Carmasin J, et al. Subjective cognitive complaints and amyloid burden in cognitively normal older individuals. Neuropsychologia. 2012;50(12):2880-2886.

6. Mitchell A, Beaumont H, Ferguson D, Yadegarfar M, Stubbs B. Risk of dementia and mild cognitive impairment in older people with subjective memory complaints: meta - analysis. Acta Psychiatrica Scandinavica. 2014;130(6):439-451.

7. Mortby ME, Lyketsos CG, Geda YE, Ismail Z. Special Issue on mild behavioral impairment and non-cognitive prodromes to dementia. Int Psychogeriatr. 2018;30(2):167-169.

8. Wise EA, Rosenberg PB, Lyketsos CG, Leoutsakos J-M. Time course of neuropsychiatric symptoms and cognitive diagnosis in National Alzheimer's Coordinating Centers volunteers. Alzheimer's \& Dementia: Diagnosis, Assessment \& Disease Monitoring. 2019;11:333-339.

9. Ismail Z, Smith EE, Geda Y, et al. Neuropsychiatric symptoms as early manifestations of emergent dementia: provisional diagnostic criteria for mild behavioral impairment. Alzheimers Dement. 2016;12(2):195-202.

10. Creese B, Brooker H, Ismail Z, et al. Mild Behavioral Impairment as a Marker of Cognitive Decline in Cognitively Normal Older Adults. Am J Geriatr Psychiatry. 2019;27(8):823-834.

11. Taragano FE, Allegri RF, Heisecke SL, et al. Risk of Conversion to Dementia in a Mild Behavioral Impairment Group Compared to a Psychiatric Group and to a Mild Cognitive Impairment Group. J Alzheimes Dis. 2018;62(1):227-238.

12. Matsuoka T, Ismail Z, Narumoto J. Prevalence of Mild Behavioral Impairment and Risk of Dementia in a Psychiatric Outpatient Clinic. J Alzheimes Dis. 2019;70(2):505-513.

13. Andrews SJ, Ismail Z, Anstey KJ, Mortby M. Association of Alzheimer's genetic loci with mild behavioral impairment. American Journal of Medical Genetics Part B: Neuropsychiatric Genetics. 2018;177(8):727-735.

14. Creese B, Brooker H, Aarsland D, Corbett A, Ballard C, Ismail Z. Genetic risk for Alzheimer disease, cognition and Mild Behavioral Impairment in healthy older adults. medRxiv. 2020:2020.2005.2013.20100800. 
medRxiv preprint doi: https://doi.org/10.1101/2020.05.24.20112284; this version posted May 25, 2020. The copyright holder for this preprint (which was not certified by peer review) is the author/funder, who has granted medRxiv a license to display the preprint in perpetuity. It is made available under a CC-BY-NC-ND 4.0 International license .

15. Naude J, Gill S, Hu S, et al. Plasma Neurofilament Light: a marker of cognitive decline in Mild Behavioural Impairment. J Alzheimes Dis. 2020;in press.

16. Lussier FZ, Pascoal TA, Chamoun M, et al. Mild behavioral impairment is associated with $\beta$-amyloid but not tau or neurodegeneration in cognitively intact elderly individuals. Alzheimers Dement. 2020;16:192-199.

17. Jack Jr CR, Bennett DA, Blennow K, et al. NIA - AA research framework: toward a biological definition of Alzheimer's disease. Alzheimers Dement. 2018;14(4):535-562.

18. Weintraub S, Salmon D, Mercaldo N, et al. The Alzheimer's disease centers' uniform data set (UDS): The neuropsychological test battery. Alzheimer disease and associated disorders. 2009;23(2):91.

19. Beekly DL, Ramos EM, Lee WW, et al. The National Alzheimer's Coordinating Center (NACC) database: the uniform data set. Alzheimer Disease \& Associated Disorders. 2007;21(3):249-258.

20. Morris JC, Weintraub S, Chui HC, et al. The Uniform Data Set (UDS): clinical and cognitive variables and descriptive data from Alzheimer Disease Centers. Alzheimer Disease \& Associated Disorders. 2006;20(4):210-216.

21. Sheikh F, Ismail Z, Mortby ME, et al. Prevalence of mild behavioral impairment in mild cognitive impairment and subjective cognitive decline, and its association with caregiver burden. Int Psychogeriatr. 2018;30(2):233244.

22. Mortby ME, Ismail Z, Anstey KJ. Prevalence estimates of mild behavioral impairment in a population-based sample of pre-dementia states and cognitively healthy older adults. Int Psychogeriatr. 2018:221-232.

23. Kaufer DI, Cummings JL, Ketchel P, et al. Validation of the NPI-Q, a brief clinical form of the Neuropsychiatric Inventory. J Neuropsychiatry Clin Neurosci. 2000;12(2):233-239.

24. Morris JC. The Clinical Dementia Rating (CDR): current version and scoring rules. Neurology. 1993;43(11):2412-2414.

25. Ismail Z, Malick A, Smith EE, Schweizer T, Fischer C. Depression versus dementia: is this construct still relevant? Neurodegener Dis Manag. 2014;4(2):119-126.

26. Panza F, Frisardi V, Capurso C, et al. Late-life depression, mild cognitive impairment, and dementia: possible continuum? Am J Geriatr Psychiatry. 2010;18(2):98-116.

27. Ismail Z, Gatchel J, Bateman DR, et al. Affective and emotional dysregulation as pre-dementia risk markers: exploring the mild behavioral impairment symptoms of depression, anxiety, irritability, and euphoria. Int Psychogeriatr. 2018;30(2):185-196.

28. Almeida O, Hankey G, Yeap B, Golledge J, Flicker L. Depression as a modifiable factor to decrease the risk of dementia. Translational Psychiatry. 2017;7(5):e1117.

29. Singh-Manoux A, Dugravot A, Fournier A, et al. Trajectories of Depressive Symptoms Before Diagnosis of Dementia: A 28-Year Follow-up Study. JAMA psychiatry. 2017. 
medRxiv preprint doi: https://doi.org/10.1101/2020.05.24.20112284; this version posted May 25, 2020. The copyright holder for this preprint (which was not certified by peer review) is the author/funder, who has granted medRxiv a license to display the preprint in perpetuity. It is made available under a CC-BY-NC-ND 4.0 International license .

30. Tapiainen V, Hartikainen S, Taipale H, Tiihonen J, Tolppanen A-M. Hospitaltreated mental and behavioral disorders and risk of Alzheimer's disease: A nationwide nested case-control study. European Psychiatry. 2017;43:92-98.

31. Gatchel JR, Rabin JS, Buckley RF, et al. Longitudinal association of depression symptoms with cognition and cortical amyloid among community-dwelling older adults. JAMA network open. 2019;2(8):e198964-e198964.

32. Hanseeuw BJ, Jonas V, Jackson J, et al. Association of anxiety with subcortical amyloidosis in cognitively normal older adults. Molecular psychiatry. 2018:1.

33. Gill S, Mouches P, Hu S, et al. A machine learning approach to predicting diagnostic category in pre-dementia. J Alzheimes Dis. 2020;in press.

34. van Harten AC, Mielke MM, Swenson-Dravis DM, et al. Subjective cognitive decline and risk of MCI: the Mayo Clinic Study of Aging. Neurology. 2018;91(4):e300-e312.

35. Wolfsgruber S, Molinuevo JL, Wagner M, et al. Prevalence of abnormal Alzheimer's disease biomarkers in patients with subjective cognitive decline: cross-sectional comparison of three European memory clinic samples. Alzheimer's research \& therapy. 2019;11(1):8.

36. Verhülsdonk S, Quack R, Höft B, Lange-Asschenfeldt C, Supprian T. Anosognosia and depression in patients with Alzheimer's dementia. Archives of gerontology and geriatrics. 2013;57(3):282-287.

37. Sánchez-Benavides G, Grau-Rivera 0 , Suárez-Calvet M, et al. Brain and cognitive correlates of subjective cognitive decline-plus features in a population-based cohort. Alzheimer's research \& therapy. 2018;10(1):123.

38. Cacciamani F, Tandetnik C, Gagliardi G, et al. Low cognitive awareness, but not complaint, is a good marker of preclinical Alzheimer's disease. $J$ Alzheimes Dis. 2017;59(2):753-762.

39. Verfaillie SC, Timmers T, Slot RE, et al. Amyloid- $\beta$ load is related to worries, but not to severity of cognitive complaints in individuals with subjective cognitive decline: the SCIENCe project. Frontiers in aging neuroscience. 2019;11:7.

40. Lee YC, Kang JM, Lee H, et al. Subjective cognitive decline and subsequent dementia: a nationwide cohort study of 579,710 people aged 66 years in South Korea. Alzheimer's Research \& Therapy. 2020;12(1):1-13.

41. Agüera - Ortiz L, Lyketsos C, Ismail Z. Comment on "Personality Changes During the Transition from Cognitive Health to Mild Cognitive Impairment".J Am Geriatr Soc. 2019.

42. Caselli RJ, Langlais BT, Dueck AC, et al. Personality changes during the transition from cognitive health to mild cognitive impairment. J Am Geriatr Soc. 2018;66(4):671-678.

43. Sutin AR, Stephan Y, Luchetti M, Terracciano A. Self - reported personality traits are prospectively associated with proxy - reported behavioral and psychological symptoms of dementia at the end of life. Int J Geriatr Psychiatry. 2018;33(3):489-494. 
medRxiv preprint doi: https://doi.org/10.1101/2020.05.24.20112284; this version posted May 25, 2020. The copyright holder for this preprint

(which was not certified by peer review) is the author/funder, who has granted medRxiv a license to display the preprint in perpetuity.

It is made available under a CC-BY-NC-ND 4.0 International license .

44. Ismail Z, Black S, Camicioli R, et al. Recommendations of the 5th Canadian Consensus Conference on the Diagnosis and Treatment of Dementia.

Alzheimer's \& Dementia. 2020;in press.

45. Cieslak A, Smith EE, Lysack J, Ismail Z. Case series of mild behavioral impairment: toward an understanding of the early stages of neurodegenerative diseases affecting behavior and cognition. Int Psychogeriatr. 2018;30(2):273-280.

46. Woolley JD, Khan BK, Murthy NK, Miller BL, Rankin KP. The diagnostic challenge of psychiatric symptoms in neurodegenerative disease: rates of and risk factors for prior psychiatric diagnosis in patients with early neurodegenerative disease. J Clin Psychiatry. 2011;72(2):126-133.

47. Reiman EM, Quiroz YT, Fleisher AS, et al. Brain imaging and fluid biomarker analysis in young adults at genetic risk for autosomal dominant Alzheimer's disease in the presenilin 1 E280A kindred: a case-control study. The Lancet Neurology. 2012;11(12):1048-1056.

48. Ismail Z, Agüera-Ortiz L, Brodaty H, et al. The Mild Behavioral Impairment Checklist (MBI-C): A Rating Scale for Neuropsychiatric Symptoms in PreDementia Populations. J Alzheimes Dis. 2017;56(3):929-938.

49. Creese B, Griffiths A, Brooker H, et al. Profile of Mild Behavioral Impairment and Factor Structure of the Mild Behavioral Impairment Checklist in Cognitively Normal Older Adults. Int Psychogeriatr. 2019; epub ahead of print:1-13.

50. Mallo SC, Ismail Z, Pereiro AX, et al. Assessing mild behavioral impairment with the mild behavioral impairment checklist in people with subjective cognitive decline. Int Psychogeriatr. 2019;31(2):231-239. 


\section{Tables}

Table 1: Representation of SCD and MBI in NIA-AA Research Framework Clinical Stage $2^{17}$

\begin{tabular}{|c|c|}
\hline NIAA-AA Stage 2 Descriptors & SCD or MBI criteria \\
\hline $\begin{array}{l}\text { Transitional cognitive decline: Cognitive } \\
\text { performance in the nonimpaired range but } \\
\text { with a subjective complaint of cognitive } \\
\text { decline, or a subtle decline measured on } \\
\text { longitudinal cognitive testing, or } \\
\text { neurobehavioral symptoms, or } \\
\text { combinations of these }\end{array}$ & $\begin{array}{l}\text { SCD: Self-experienced persistent decline in } \\
\text { cognitive capacity in comparison with a } \\
\text { previously normal status and unrelated to } \\
\text { an acute event, normal age-, gender-, and } \\
\text { education-adjusted performance on } \\
\text { standardized cognitive tests } \\
\text { MBI: Behavior and personality changes can } \\
\text { precede cognitive decline and present in } \\
\text { absence of cognitive changes, or can } \\
\text { accompany cognitive symptoms }\end{array}$ \\
\hline $\begin{array}{l}\text { Represents a change from individual } \\
\text { baseline within past } 1-3 \text { years, and } \\
\text { persistent for at least } 6 \text { months. Although } \\
\text { cognition is the core feature, mild } \\
\text { neurobehavioral changes-for example, } \\
\text { changes in mood, anxiety, or motivation- } \\
\text { may coexist. In some individuals, the } \\
\text { primary complaint may be neurobehavioral } \\
\text { rather than cognitive. Neurobehavioral } \\
\text { symptoms should have a clearly defined } \\
\text { recent onset, which persists and cannot be } \\
\text { explained by life events }\end{array}$ & $\begin{array}{l}\text { SCD: Onset of cognitive symptoms within } \\
\text { the last } 5 \text { years (SCD-plus criterion }{ }^{3} \text { ) } \\
\text { MBI: Changes in behavior or personality, } \\
\text { starting later in life representing a clear } \\
\text { change from usual behavior or personality, } \\
\text { and persisting for at least } 6 \text { months; not } \\
\text { better accounted for by psychiatric } \\
\text { conditions (including adjustment } \\
\text { difficulties secondary to life events) }\end{array}$ \\
\hline
\end{tabular}


Table 2. Summary statistics for demographics and MBI-C score by patient grouping in those with baseline $C D R=0(n=2769)$.

\begin{tabular}{|c|c|c|c|c|c|c|}
\hline $\begin{array}{l}\text { Mean/ Proportion } \\
\text { (SD/SE) }\end{array}$ & $\begin{array}{c}\text { MBI-/SCD- } \\
(n=1536 ; \\
55.47 \%)\end{array}$ & $\begin{array}{c}\text { MBI-/SCD+ } \\
(n=254 ; \\
9.17 \%)\end{array}$ & $\begin{array}{c}\text { MBI+/SCD- } \\
(n=743 ; \\
26.83 \%)\end{array}$ & $\begin{array}{c}\text { MBI+/SCD+ } \\
(n=236 ; \\
8.52 \%)\end{array}$ & p-value & $\begin{array}{l}\text { Overall } \\
(n=2769)\end{array}$ \\
\hline Age & $72.07(9.22)$ & $74.80(8.88)$ & $73.46(9.11)$ & $74.30(9.53)$ & $<0.001$ & $\begin{array}{c}73.00 \\
{[67.00,80.00]}\end{array}$ \\
\hline Sex (\% female) & $1045(68.0)$ & $160(63.0)$ & 402 (54.1) & $147(62.3)$ & $<0.001$ & $1754(63.3)$ \\
\hline $\begin{array}{c}\text { Education } \\
\text { (\% more than high school) }\end{array}$ & $1279(83.3)$ & $205(80.7)$ & $621(83.6)$ & $200(84.7)$ & 0.656 & $2305(83.2)$ \\
\hline $\begin{array}{c}\text { Ethnicity } \\
\text { (\% Caucasian) }\end{array}$ & 1167 (75.9) & $186(73.2)$ & $664(89.4)$ & 209 (88.6) & $<0.001$ & $2226(80.3)$ \\
\hline $\begin{array}{l}\text { Marital Status } \\
(\% \text { married })\end{array}$ & 874 (56.9) & $133(52.4)$ & $447(60.2)$ & 131 (55.5) & 0.161 & $1585(57.2)$ \\
\hline $\begin{array}{l}\text { History of hypertension } \\
\text { (\% present) }\end{array}$ & 609 (39.6) & $120(47.2)$ & $360(48.5)$ & 99 (41.9) & $<0.001$ & $1188(42.9)$ \\
\hline $\begin{array}{l}\text { Hypercholesterolemia } \\
\text { (\% present) }\end{array}$ & $537(35.0)$ & $97(38.2)$ & 331 (44.5) & 97 (41.1) & 0.191 & $1062(38.4)$ \\
\hline $\begin{array}{l}\text { Diabetes } \\
\text { (\% present) }\end{array}$ & $118(7.7)$ & $25(9.8)$ & $70(9.4)$ & $17(7.2)$ & 0.500 & $230(8.3)$ \\
\hline MBI Score & $0.00(0.00)$ & $0.00(0.00)$ & $1.90(1.51)$ & $1.82(1.23)$ & $<0.001$ & $\begin{array}{c}1.00 \\
{[0.00,2.00]}\end{array}$ \\
\hline CDR Score at 3 years & $0.03(0.12)$ & $0.08(0.19)$ & $0.13(0.31)$ & $0.16(0.25)$ & $<0.001$ & $\begin{array}{c}0.00 \\
{[0.00,1.00]}\end{array}$ \\
\hline
\end{tabular}




\section{Figure Titles}

Figure 1: Cognitive and behavioral pre-dementia risk axes

Figure 2: Flowchart of participants from NACC included for analysis.

Figure 3: a) Odds of $\mathrm{CDR}>0$ after three years vs. MBI/SCD grouping; b) CDR score at follow up (baseline $\mathrm{CDR}=0)$; c) Odds of dementia $(\mathrm{CDR} \geq 1)$ after 3 years vs. MBI/SCD grouping. Adjusted Odds Ratios (AORs) are adjusted for age, sex, ethnicity and hypertension. 
medRxiv preprint doi: https://doi.org/10.1101/2020.05.24.20112284; this version posted May 25, 2020. The copyright holder for this preprint (which was not certified by peer review) is the author/funder, who has granted medRxiv a license to display the preprint in perpetuity.

\section{It is made available under a CC-BY-NC-ND 4.0 International license .}

\section{Figure 1}

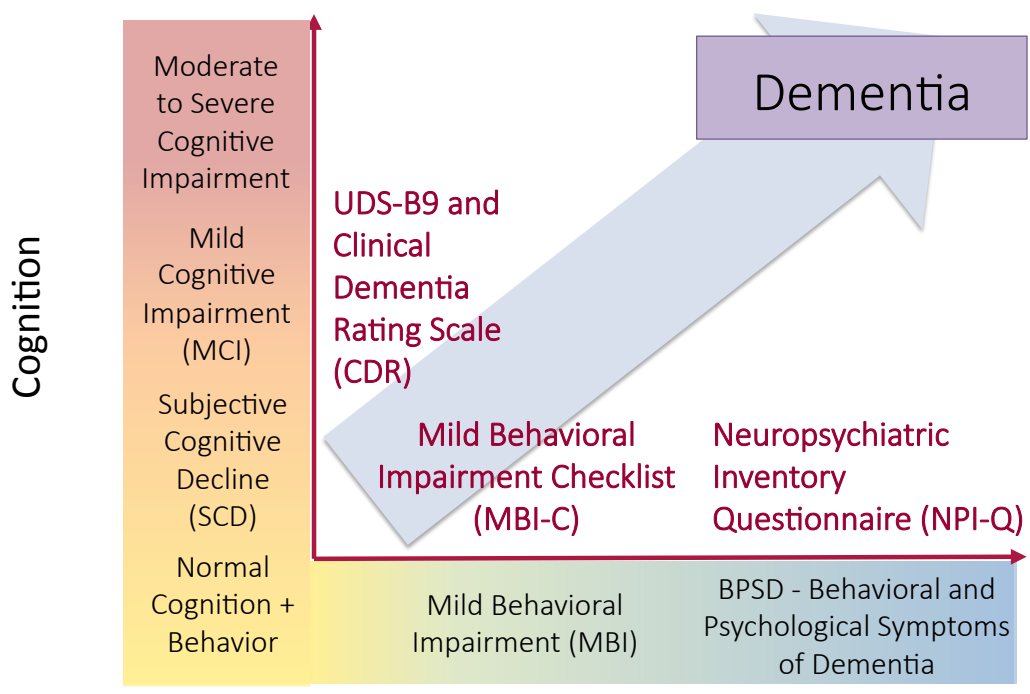

\section{Behavior}


medRxiv preprint doi: https://doi.org/10.1101/2020.05.24.20112284; this version posted May 25, 2020. The copyright holder for this preprint (which was not certified by peer review) is the author/funder, who has granted medRxiv a license to display the preprint in perpetuity.

It is made available under a CC-BY-NC-ND 4.0 International license .

\section{Figure 2}
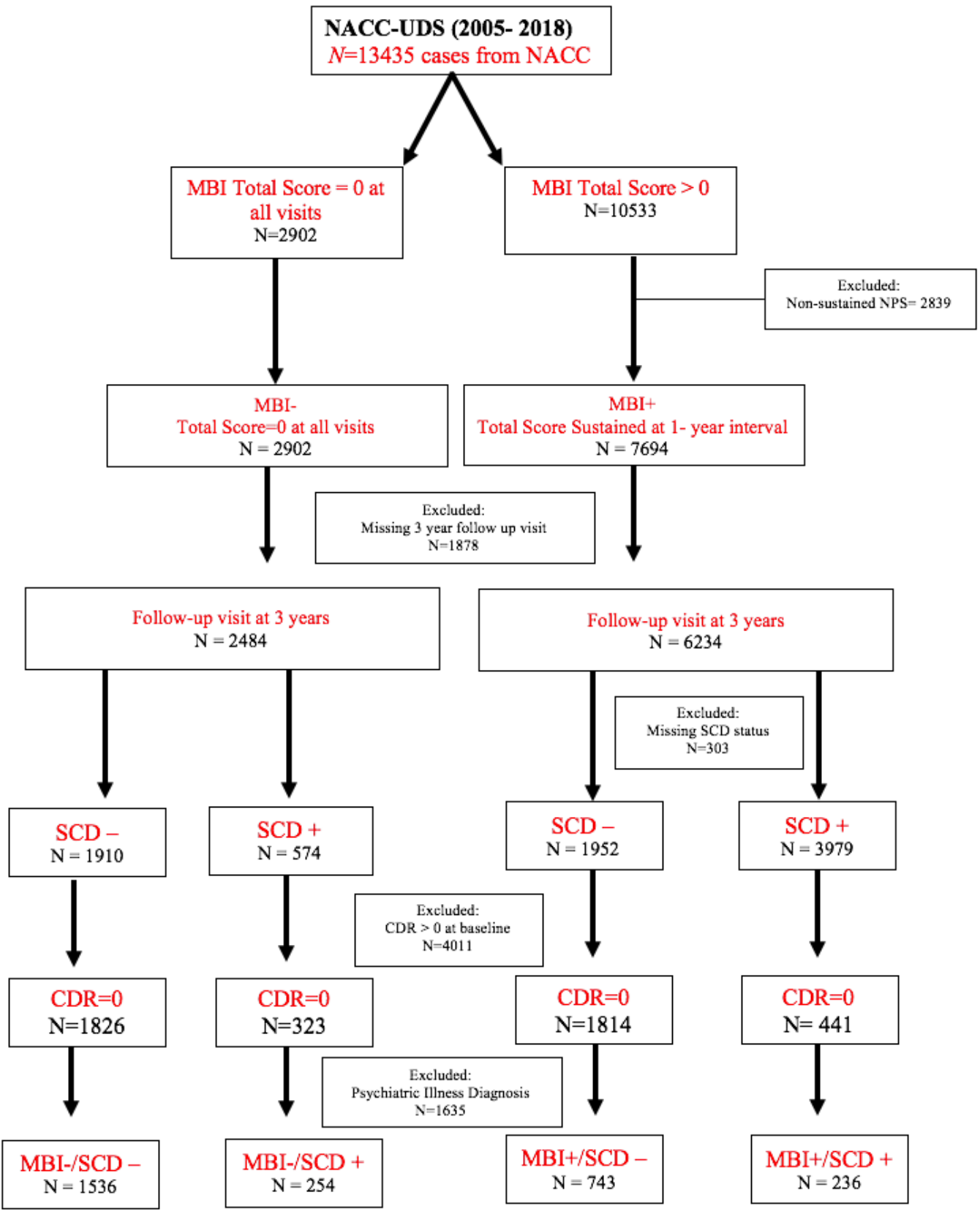

up visit at 3 years

$$
\mathrm{N}=2484
$$

Follow-up visit at 3 years $\mathrm{N}=6234$
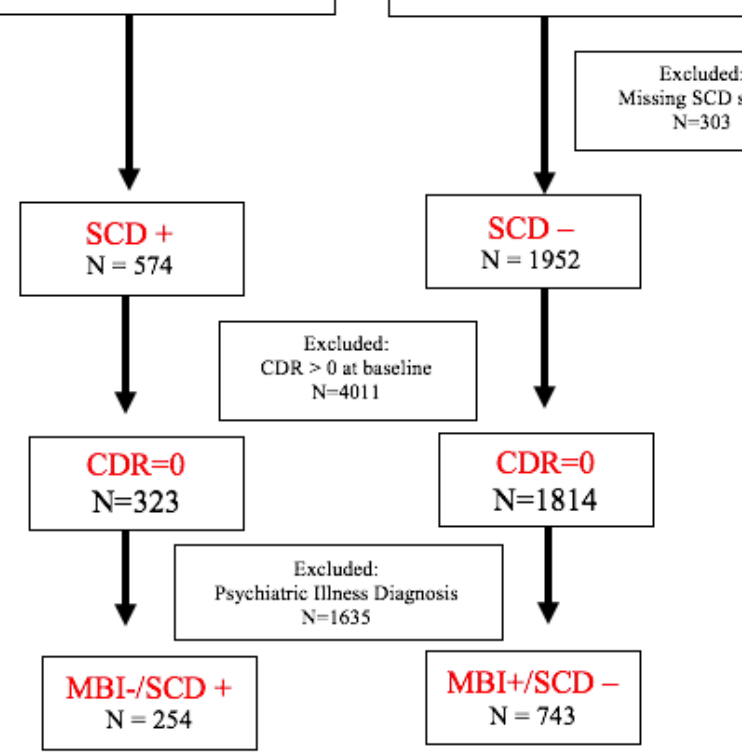
$\mathrm{N}=303$

$$
\text { D status }
$$


medRxiv preprint doi: https://doi.org/10.1101/2020.05.24.20112284; this version posted May 25, 2020. The copyright holder for this preprint (which was not certified by peer review) is the author/funder, who has granted medRxiv a license to display the preprint in perpetuity.

It is made available under a CC-BY-NC-ND 4.0 International license .

\section{Figure 3}
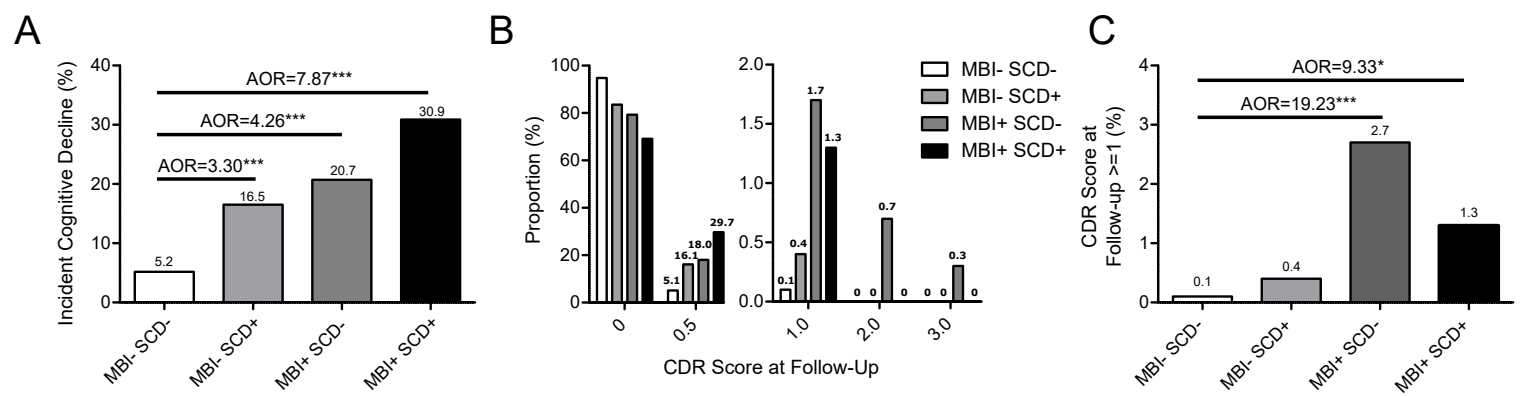